\title{
Erratum to: International Federation for the Surgery of Obesity and Metabolic Disorders. XIV World Congress
}

Published online: 20 October 2009

(C) Springer Science + Business Media, LLC 2009

Erratum to: OBES SURG

DOI 10.1007/s11695-009-9904-9

Palais des Congrès (Porte Maillot) - Paris, France August 26-29, 2009

Please note the below errors in the original publication, which appears in the August issue (volume 19, issue 8, pp. 953-1076.

\section{O-001 - Speaker and affiliation list incorrect}

Presenter: Marco Bueter (Imperial College London, Hammersmith Hospital, United Kingdom)

Co-authors: M. Bueter ${ }^{1,2}$, C. Loewenstein ${ }^{3}$, H. Ashrafian ${ }^{1}$, S. R. Bloom ${ }^{1}$, T. A. Lutz ${ }^{3}$, C. W. le Roux ${ }^{1}$

1. Dept. of Investigative Medicine, Hammersmith Hospital, Imperial College London London 2. Dept. of Surgery, University of Wrzburg Wrzburg 3. Institute of Veterinary Physiology, Vetsuisse Faculty, University of Zurich Zurich

O-004 - Speaker name incorrect

\section{A. Lazzati}

The online version of the original article can be found at http://dx.doi. org/10.1007/s11695-009-9904-9
O-039 - Co-author list incorrect

Presenter: M. Pellen (Castle Hill Hospital, Hull, Cottingham, United Kingdom)

Co-authors: C. J. O’Boyle ${ }^{1}$, P. C. Sedman ${ }^{2}$, P. Jain ${ }^{2}$

1. Bon Secours Hospital Cork 2. Castle Hill Hospital Hull O-040 - Co-author list incorrect

Co-authors: J. Barry, M. Arumagasamy, J. Brocklehurst, S. Javed, BS Aditya R. Macadam, D. Kerrigan (Wirral, UK)

P-008 - Speaker list incorrect

Presenter: Marco Bueter (Imperial College London, Hammersmith Hospital, United Kingdom)

Co-authors: M. Bueter ${ }^{1,2}$, C. Loewenstein ${ }^{3}$, H. Ashrafian ${ }^{1}$, S. R. Bloom ${ }^{1}$, T. A. Lutz ${ }^{3}$, C. W. Le Roux ${ }^{1}$

1. Imperial College London, Hammersmith Hospital, Dept. of Investigative Medicine London United Kingdom 2. Dept. of Surgery, University of Würzburg Würzburg Germany 3. Institute of Veterinary Physiology, Vetsuisse Faculty, University of Zurich Zurich Switzerland

P-011 - Speaker list incorrect

Presenter: Marco Bueter (Imperial College London, Hammersmith Hospital, United Kingdom)

Co-authors: M. Bueter ${ }^{1,2}$, H. Ashrafian ${ }^{1}$, A. H. Frankel ${ }^{3}$, F. W. Tam ${ }^{3}$, R. J. Unwin ${ }^{4}$, S. R. Bloom ${ }^{1}$, C. W le Roux ${ }^{1}$

1. Dept. of Investigative Medicine, Hammersmith Hospital, Imperial College London London United Kingdom 2. 
Dept. of Surgery, University of Würzburg Würzburg Germany 3. Imperial Kidney and Transplant Institute, Hammersmith Hospital, Imperial College London London United Kingdom 4. Centre for Nephrology, University College London Medical School, Royal Free Campus London United Kingdom

\section{P-091 - Co-author list incorrect}

Presenter: M. Pellen (Castle Hill Hospital, Hull, Cottingham, United Kingdom)

Co-author: C. J. O’Boyle ${ }^{1}$, P. C. Sedman ${ }^{2}$, P. Jain ${ }^{2}$

1. Bon Secours Hospital Cork 2. Castle Hill Hospital Hull

\section{P-188 - Result section incorrect}

Results Between 2001 and 2008, 1000 patients submitted to bariatric surgery by the same surgeon of the CITOM were analyzed. Open gastric bypass without contensor ring correspond to 136 of these procedures, 331 correspond to open gastric bypass with contensor ring, 173 correspond to laparoscopic gastric bypass without contensor ring and 360 correspond to laparoscopic gastric bypass with contensor ring. The incidence of stenosis is $5,88 \%$ in the open gastric bypass without contensor ring; $3,02 \%$ in the open gastric bypass with contensor ring; $3,47 \%$ in the laparoscopic gastric bypass without contensor ring and $1,11 \%$ in the laparoscopic gastric bypass with contensor ring. 